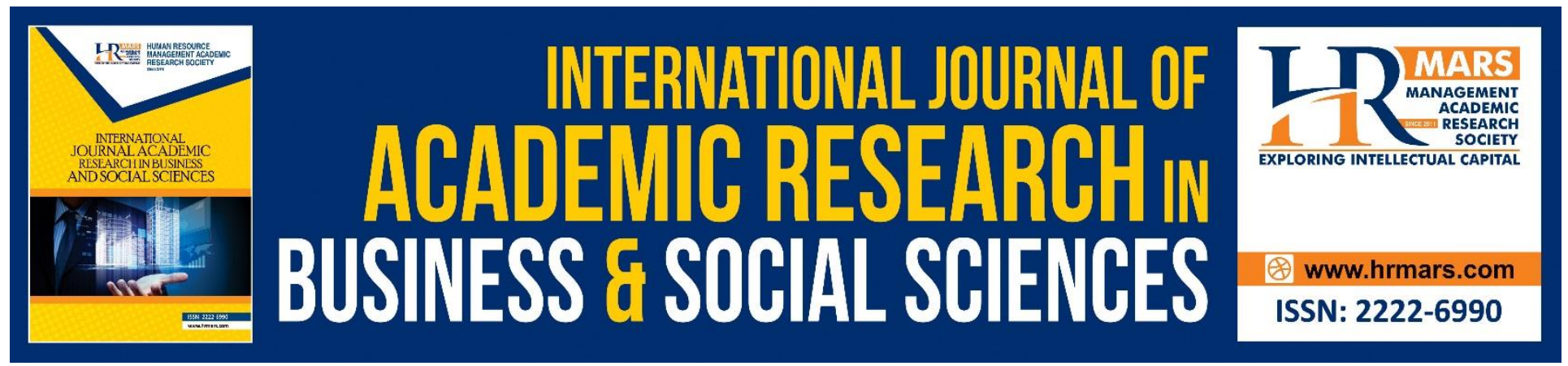

\title{
Comparative Study of Dengue Prevention Measures in Malaysian Construction Site
}

\section{Nur Afrina Qistina Ahmad Halmi, Haliza Abdul Rahman}

To Link this Article: http://dx.doi.org/10.6007/IJARBSS/v10-i16/8295

DOI:10.6007/IJARBSS/v10-i16/8295

Received: 14 September 2020, Revised: 18 October 2020, Accepted: 01 November 2020

Published Online: 29 November 2020

In-Text Citation: (Halmi \& Rahman, 2020)

To Cite this Article: Halmi, N. A. Q. A., \& Rahman, H. A. (2020). Comparative Study of Dengue Prevention Measures in Malaysian Construction Site. International Journal of Academic Research in Business and Social Sciences, 10(16), 109-119.

\section{Copyright: (c) 2020 The Author(s)}

Published by Human Resource Management Academic Research Society (www.hrmars.com)

This article is published under the Creative Commons Attribution (CC BY 4.0) license. Anyone may reproduce, distribute, translate and create derivative works of this article (for both commercial and non-commercial purposes), subject to full attribution to the original publication and authors. The full terms of this license may be seen at: http://creativecommons.org/licences/by/4.0/legalcode

Special Issue: Youth and Community Wellbeing: Issues, Challenges and Opportunities for Empowerment V2, 2020, Pg. 109 - 119

Full Terms \& Conditions of access and use can be found at http://hrmars.com/index.php/pages/detail/publication-ethics 


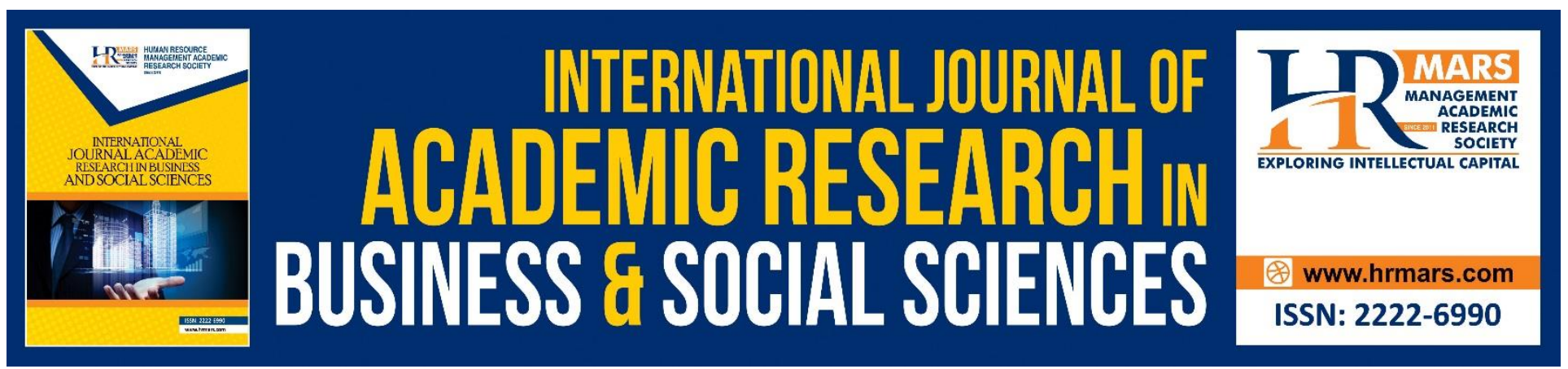

\title{
Comparative Study of Dengue Prevention Measures in Malaysian Construction Site
}

\author{
Nur Afrina Qistina Ahmad Halmi, Haliza Abdul Rahman \\ Institute for Social Science Studies, Universiti Putra Malaysia, 43400 Serdang, Selangor, Malaysia \\ Department of Environmental and Occupational Health, Faculty of Medicine and Health Sciences, \\ Universiti Putra Malaysia, 43400 Serdang, Selangor, Malaysia \\ Email: dr.haliza@upm.edu.my
}

\begin{abstract}
Dengue cases have been a significant health threat to Malaysia for more than a century since the year 1902, and this situation has worsened every year. This paper covered the comparative study to analyse further the differences and similarities between countries such as Singapore regarding the existing guidelines and legislation implemented towards dengue prevention measures. The method of this study is using a depth literature review which adopted from various and related documents such as journals, reports, proceedings, and Government Act. A total of 20 published article systematic surveys were included, a complete of 28 relevant references were identified by database literature search. Thus, a comparative analysis was conducted to compare and contrast dengue preventive measures in Malaysia and Singapore, suffering from dengue cases. Therefore, a comparison of perspectives legislations between Singapore and Malaysia can identify the efficiency of dengue prevention and the effectiveness of enforcement, which available to be implemented in Malaysia. In conclusion, it is essential to improve the legislations and guidelines for strengthening dengue prevention in Malaysia. Indirectly, it can finally solve the dengue issue in this country. Therefore, the government, especially the Ministry of Health, needs to reconsider these preventive measures to curb dengue cases in Malaysia.
\end{abstract}

Keywords: Dengue, Prevention Measure, Malaysian Construction Site, Legislations

\section{Introduction}

The World Health Organization (WHO) states that $17 \%$ of all infectious diseases leading to the world's fastest-growing vector are dengue. Dengue has led to a 30 -fold increase in terms of contagious diseases over the last 50 years. In Malaysia, dengue is well known in the category of a group of high burden diseases (Basar \& Ismail, 2016). Various efforts have been made by the Ministry of Health Malaysia to combat the number of dengue cases. In Malaysia as well, dengue is a significant cause of 
morbidity and death. Thus, dengue has been listed as the most common disease throughout the year (Ahmad et al., 2018).

Malaysia has existed with different serotype dengue. This is because the virus that causes dengue is also an epidemic borne by an arthropod or called an arbovirus with four different serotypes that do not offer permanent cross-immunity to each other. Initially, the Malaysian Government achieved a decrease within the amount of dengue cases in 2017, with 83,849 new cases reported compared to an entire of 101,357 cases within the previous year. However, Malaysia has experienced a sharp increase within the quantity of infected individuals in 2019 and 2020. The number of dengue cases continues to increase throughout the year and causes rapid global spread and cannot stop this infectious disease (Hamdan \& Kilicman, 2021).

Until now, the Malaysian Government has not approved the use of the dengue vaccine. Besides, Malaysian Government initiatives can be a control program that relies solely on vector control management and dengue awareness campaigns. The place best known for the major contributors to the number of dengue cases is in development locations. Construction projects in Malaysia have a high potential for inbreeding Aedes mosquitoes (Basar, Ismail, \& Nasir, 2017).

Comparative analysis of dengue prevention measures implemented in other countries affected of dengue diseases such as Singapore. This paper represents the current implementation used in Malaysia's construction project on dengue cases and compares them with Singapore. Therefore, the implementation of guidelines and legislation used to fight dengue is described in more detail in this paper. Therefore, this paper covers a comparative study to analyse further the differences and similarities between countries such as Singapore regarding guidelines and legislation applicable to dengue prevention measures.

\section{Methods}

In this paper, the research approach chosen are depth literature on dengue prevention in Malaysia. This article was focusing on the existing legislation on dengue in Malaysian Contruction Industry. Extensive literature was identified from several and associated documents such as reports, proceedings, journals, and Government acts. The issues will discuss further in the next section.

\section{Dengue}

Dengue is defined as a virus known as dengue when it can be spread to humans through mosquito bites of the Aedes species (Ae. Aegypti or Ae. Albopictus). Aedes aegypti has been studied by scientists and is considered a major species involved in transmitting the dengue virus to humans (Lim et al., 2010; Benard \& Felicia, 2015). This Aedes mosquito species also only spreads dengue fever when it has been infected. The efficient dengue virus vector is explained by its ability to adapt to different environments, different options for human habitat, and bypass-oviposition behavior ( $\mathrm{Ng}$ et al., 2009). Female mosquitoes or called Ae. aegypti will consume human host blood, causing frequent contact between vectors and humans. This anthropophilic tendency is considered to be the element that embodies Ae. aegypti is more efficient in spreading the dengue virus than Ae. albopictus that feeds blood to humans and animals (Prevention, 2009). A female mosquito will eat a lot of blood (Dye, 1986), and each cycle of female mosquito eggs will increase its ability to spread the dengue virus. This female mosquito species will also look for food during the day when humans are currently active (Ahmad et al., 2018). Aedes albopictus is a secondary vector of the dengue virus in Southeast 
Asia. Still, it has also been documented as a single vector during several outbreaks in which Ae. aegypti is absent (Kyle \& Harris, 2008). Dengue has infected more than 100 countries worldwide. About forty percent of the world's population of 3 billion people have lived in areas at risk of dengue. The areas at breeding Aedes mosquitoes can spread dengue (Prevention, 2009).

Therefore, the public should be responsible for endangering this species to reduce the dengue virusinfected in its environment. The species is a mosquito that comes from the forest but has adapted to human areas both in rural and urban areas in Malaysia ( $\mathrm{H}$ et al., 2015). This species also prefers the outdoor environment for leisure activities such as picnics, exercise, hill climbing, etc. However, this species also likes to bite humans while resting indoors (Perich et al., 2003). According to the World Health Organization, in 2020, the number of dengue cases increased by 2.2 million in 2015, increasing the number of reported dengue cases to 3.2 million. Basar, Nawi, \& Ismai, (2018) said that a severe increase and precautions should be taken. Apart from that, dengue fever has been common in Malaysia since the first case of dengue was reported in 1902. Despite initiatives undertaken by the Ministry of Health to curb the disease, the amount of cases has increased. in line with WHO, the amount of recent cumulative cases in Malaysia from 1 January to 2 March 2019 is 157\% above the identical period in 2018.

The state that contributes the foremost to the rise in dengue in Malaysia is that the state of Selangor. a complete of 79,151 dengue cases were reported until the top of July 2019 throughout the country. Selangor's government has contributed over $50 \%$ of cases ( $n=40,849,51.6 \%$ to the world level (Harapan et al., 2018). It is often linked that climate change may be one of the factors increasing the incidence of infectious diseases. Studies have been made that climate change is not the only factor causing a sharp increase in Malaysia's number of dengue cases (Ong, 2016).

Factors for the increase in dengue cases in the tropics and sub-tropics are influenced by complex factors such as changes in the environment, weather, urbanisation, and quality of vector control services in urban areas (Cheong, Burkart, Leitão, \& Lakes, 2013). Dengue cases have been a significant health threat to Malaysia for more than a century since 1902. This situation has worsened every year, and the Malaysian Ministry of Health needs to address this problem. Therefore, the Government needs to know the influence of government support, climate change, community attitudes, population growth, and the environment against dengue infection. This study also considers the environment as a mediator construct because past literature shows its role in the dengue infection model (Muhammad Azami, Salleh, Neoh, Syed Zakaria, \& Jamal, 2011).

One world has been currently told that no effective and safe vaccine is immunising against the dengue virus (Abdelrazec, Bélair, Shan, \& Zhu, 2016). Although some studies on developing a perfect vaccine are underway, no one else states that it has been successfully adopted (Agusto \& Khan, 2018). The latest version of the dengue vaccine does not provide a satisfactory level of protection against the disease (Capeding et al., 2014). Therefore, the control of the transmission of dengue cases can be reduced if the focus is on its vector mosquitoes by reducing the population size. Also, other vector control strategies can include ecological management, for example, elimination of human-made mosquito breeding grounds, application of pesticides or predators suitable to outdoor water containers, use of personal and household protection (such as window coverings, long-sleeved clothing, mosquito repellent, sleeping nets treated with insecticides, evaporators, and coils), and available insecticide sprayers (Abidemi \& Aziz, 2020). 


\section{Dengue in Malaysia Construction Projects}

One of the hotspot locations for mosquito breeding is in the construction project area (Ministry of Health Malaysia, 2011). According to Sampaio et al. (2009), several studies have focused on dengue breeding in construction projects. This is because construction sites have become the highest contributing factor to the increase in Malaysia's dengue cases. In construction sites, solid waste management is vital to reduce dengue breeding in the area. Besides, recycling public construction rubble is one of the sanitation measures to promote the reduction of dengue-related diseases in Malaysia jointly. Again, cases of dengue infection can be reduced through environmental education. This is important to ensure public measures' efficiency when identifying high-density breeding areas, especially macro reservoirs in urban areas (Sampaio, Kligerman, \& Junior, 2009). Various research studies are conducted to seek out methods and techniques to regulate and stop dengue outbreaks, especially in risk assessment, control methods, human behavior, vaccine development, and dengue treatment (Chang, Fuller, Carrasquillo, \& Beier, 2014).

Malaysia's National Dengue Control System records an increase in Malaysia's dengue cases from 2013 to 2019 (Nazni et al., 2019). A sudden increase in dengue cases can lead to indirect deaths and losses, such as loss of productivity due to disease and premature death. Although several studies have been conducted to identify ways to control dengue fever, this study's results are still insufficient (Phillips, 2008). In addition, in most construction projects, construction workers neglect their responsibility to ensure that there is no water reservoir in the rubbish or construction materials that could be dengue breeding areas. Many of them have neglected their duty to prevent mosquitoes' breeding in unclean environments (Basar \& Ismail, 2016). Due to a couple of construction workers' attitudes, this is often one among the proofs why construction projects are one among the most contributors to the rise in Malaysia's dengue cases. In Malaysia, measures are implemented to forestall and control dengue cases. In Malaysia, measures have been implemented to prevent and control dengue cases. One of the standards is to conduct inspections, use of larvae, and enforcement of the Disease Destroying Disease Act 1975 (Act 154); and the Prevention and Control of Infectious Diseases Act 1988 (Act 342). Enforcement has stipulated that, for construction projects to reproduce Aedes larvae, enforcement will use the Insect Destruction of Disease Destruction Act 1975 (Act 154). The Act emphasizes that individuals find breeding of Aedes larvae in and around the premises. If a development project is found to breed mosquitoes, fines and fines are imposed on the development project, and therefore the developer or contractor is asked to pay the fines and fines given to them. After that, the developer or contractor is asked to eliminate any factors that could potentially contribute to the breeding of mosquito larvae. The Prevention and Control of Infectious Diseases Act 1988 (Act 342) may be a law enacted to include laws to prevent and control infectious diseases. This Act is used to manage the spread of infectious diseases, and this provision also provides for offenses and punishments for persons or premises found to spread vector-borne diseases. (Basar \& Ismail, 2016).

\section{Implementation Enforced in Malaysia}

In Malaysia, there are two laws and legislation to handle the difficulty of dengue. These are a) Destruction of Disease Bearing Insects Act 1975 (Act 154) which came into force on 23 August 1987; and b) the Prevention and Control of Infectious Diseases Act 1988 (Act 342). implementation enforced in malaysia 


\section{Legislation Implemented in Malaysia Construction Projects}

The Ministry of Health reports that construction projects are the best within the percentage of sectors contributing to the high number of dengue cases in Malaysia. Construction projects are listed as mosquito breeding grounds. Therefore, to cut back the quantity of dengue cases in Malaysia's construction projects, an Act is employed to enforce uncontrolled conditions (Basar, Nawi, et al., 2018). The principal Act associated with dengue cases in Malaysia is that the Destruction of DiseaseCarrying Insects Act 1957 (Act 154). Provisions used for wrongdoing in breeding mosquitoes are under Section 23 (Act 154).

\section{Guidelines Implemented in Malaysia}

Table 1: Existing Guidelines on Dengue Prevention Implemented in Malaysia

Title
International
Health Regulation

(2005)

\section{Summary}

The International Health Regulations (2005) are published, taking into consideration international travel and trade growth. The emergence or re-emergence of worldwide disease threats and other public health risks to stop, protect, control, and supply public health response to the spread of international disease in an exceedingly manner like and limited to public health risks, and to avoid unnecessary disruption within the past international trade and trade.

Global Strategy for Dengue Prevention and Control (2012 - 2020) 2020, aims to enhance the case as tropical diseases have shocked the
The Global Strategy for the Prevention and Control of Dengue, 2012planet. Global Strategy emphasizes new opportunities, opened by national experience and hate research, and vaccines, which may be taken to cut back morbidity and mortality, rationalize disease responses, and develop capabilities that increase resilience to future epidemics. Besides, Global strategy promotes an integrated approach to vector management and sustainable operational measures in the slightest degree levels. Its guiding principles are to coordinate prevention, entomological and epidemiological surveillance, and case management with existing health systems, ensuring that efforts are coherent, sustainable, cost-effective, and ecological. The Asia-Pacific Strategy for Emerging Diseases (ASPED) provides a framework for strengthening national and regional capabilities to manage emerging diseases, improve pandemic preparedness and go with core capacity requirements of the International Health Regulations (2005).

Asia Pacific

Strategy for The Asia-Pacific Strategy for Emerging Diseases (ASPED) provides a Emerging Disease, ASPED (2010) framework for strengthening national and regional capabilities to manage emerging diseases, improve pandemic preparedness and go with core capacity requirements of the International Health Regulations (2005). 
Asia-Pacific

Dengue Strategic

Plan (2008 - 2015)
The Asia Pacific Dengue Strategic Plan (2008 - 2015) was prepared in response to the increasing threat from dengue, spreading to new geographical areas, and causing high deaths during the first phases of the epidemic. Asia Pacific Dengue Strategic Plan is to reverse the increasing trend of dengue in countries within the Asia Pacific region. These guidelines are an adaptation of the regional approach through ongoing collaboration between governments and partnerships to enable countries to implement evidence-based interventions and best practices. additionally, the strategic plan is to right away detect, characterize, and stop outbreaks and limit outbreaks of effective dengue prevention and control.

Source: (Basar \& Ismail, 2016)

\section{Dengue in Other Country}

A comparative study between Malaysia and Singapore has been conducted to research the differences in enforcement by countries. Statistics from the planet Health Organization show a decrease within the number between the 2 countries, showing that efficient dengue prevention measures are implemented in combating the difficulty by both countries. (World Health Organization, 2020). During the 38th week, 2020, a complete of 1,361 cases of dengue were reported, bringing the full number of cases accumulated to 75,804 as of September 19, 2020. this is often a decrease from 98,184 cases for the identical period last year. One death because of dengue was reported within the 38th week with a cumulative number of 124 deaths in 2020, compared to 143 deaths within the same period in 2019. Dengue activity has decreased since the 33rd week and under the cases reported in week 25- 38 2019. In contrast, in Singapore, within the 37th week, 2020, only 725 cases of dengue were reported in Singapore, which is less than Malaysia's cases. a complete of 28,943 cases were reported on 12 September 2020 (World Health Organization, 2020)

\section{Comparative Study on Legislations and Guidelines}

Table 2: Comparative study on the legislations and guidelines implemented in Malaysia and Singapore

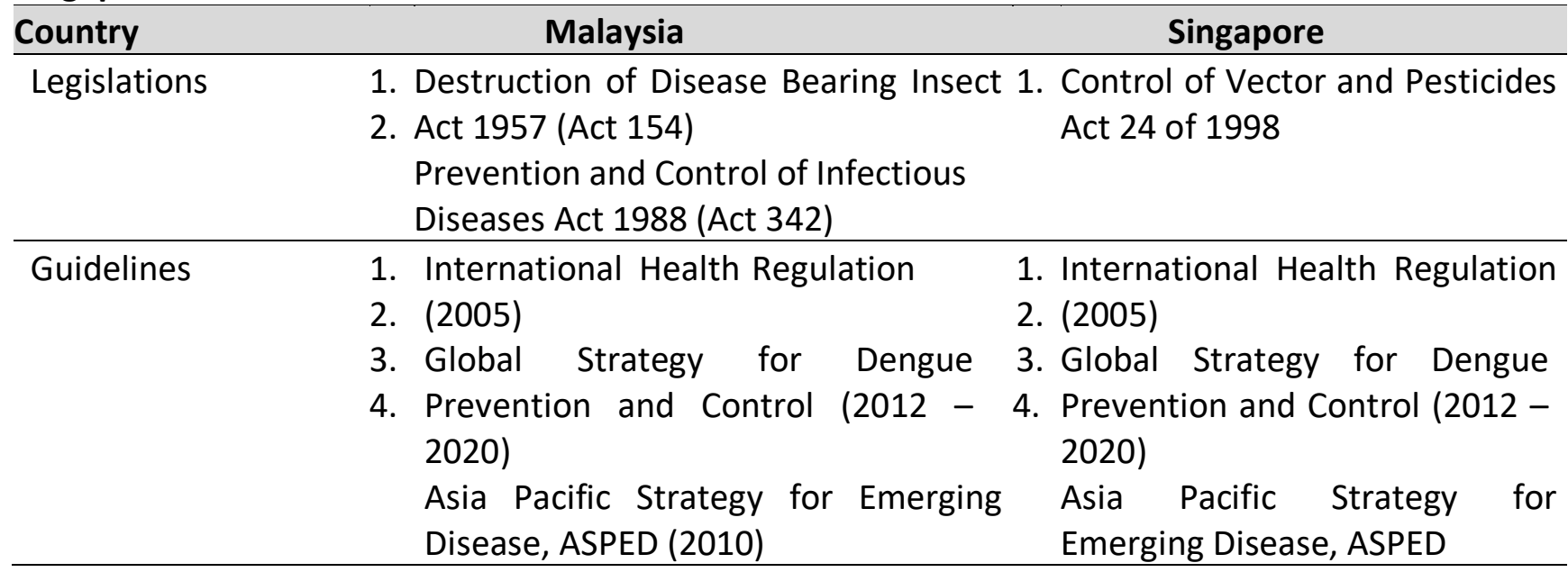




$$
\begin{aligned}
& \text { Asia Pacific Dengue Strategic Plan } \\
& (2008-2015)
\end{aligned}
$$

(2010)

Asia Pacific Dengue Strategic

Plan (2008 - 2015)

\begin{tabular}{lcc}
\hline $\begin{array}{l}\text { Implementing the } \\
\text { International Health } \\
\text { Regulations (2005) }\end{array}$ & YES \\
\hline $\begin{array}{l}\text { Governing Body for Ministry of Health (MoH), Malaysia } \\
\text { Dengue Issues }\end{array}$ & $\begin{array}{c}\text { National Environment } \\
\text { (NEA), Singapore }\end{array}$ \\
\hline $\begin{array}{l}\text { Location: High Dengue } \\
\text { Cases }\end{array}$ & Selangor & Geylang Road \\
\hline $\begin{array}{l}\text { Reported Dengue Cases } \\
\text { in 2016 compare to }\end{array}$ & HIGHER & LOWER \\
2015 & & HIGH \\
\hline $\begin{array}{l}\text { Level of } \\
\text { Enforcement } \\
\text { Implemented }\end{array}$ & LOW & \\
\hline
\end{tabular}

\section{Source: (Basar, Ismail, \& Nasir, 2018)}

In Table 2, several similarities are identified regarding the enforcement implemented by the two countries. First, the rules implemented by Malaysia and Singapore follow the policies that are published by the world Health Organization (WHO) prepared for adoption by the Southeast Asian region. Malaysia and Singapore have implemented: International Health Regulations (2005), Global Strategies for Dengue Prevention and Control (2012-2020), Asia Pacific Strategy for Emerging Diseases, ASPED (2010), Asia-Pacific Dengue Strategic Plan (2008 - 2015). Guidelines are accustomed prevent and control dengue within the Southeast Asian region. Additionally, to the rules, Malaysia and Singapore have said most procedures and methods to stop and control emerging dengue cases. Legislation employed by Malaysia and Singapore uses different laws on the prevention and management of dengue. Malaysia has enacted two legal frameworks: The Destruction of DiseaseCarrying Insects Act 1957 (Act 154) and therefore the Prevention and Control of Infectious Diseases Act 1988 (Act 342). Act 154 provides for the removal and control of disease-carrying insects and also the examination and medical treatment of persons littered with insect-borne diseases; moreover, Act 342 was enacted to forestall and control Malaysia's infectious diseases. In Singapore, the country has implemented the Vector Control and Pesticides Act 1998 (Act 24). Provisions on vector destruction and vector-borne disease control are provided (Basar et al., 2017).

Moreover, the Vector and Pesticide Control Act is additionally an upgraded version of the previous Disease Insect Destruction Act (DDBIA) implemented in Singapore. The provisions of the Vector and Pesticide Control Act also provide for the control of the sale and use of pesticides and vector repellents to supply registration, licensing, and certification of persons involved in vector control occupations. the prevailing law in Singapore seems to be more efficient in combating dengue cases in Singapore. The DDBIA Act implemented in Singapore is taken into account comprehensive in terms of its enforcement and therefore the severity of punishment for offenders compared to the Vector and Pesticide Control Act (Basar \& Ismail, 2016). 
It is also noted that the dengue epidemic body plays a very important role in implementing relevant preventive measures. The body in power for Malaysia is that the Ministry of Health (MOH). For Singapore, the National Environment Agency (NEA) is entrusted with preventing dengue outbreaks. Both governing bodies have to play their part in preventing dengue problems in both countries to scale back dengue cases.

Based on the statistical data analysis of dengue cases recorded in both countries, it had been identified that compared to 2015, Malaysia experienced a rise in dengue cases in 2016. the quantity of dengue cases recorded in Malaysia remains increasing despite implementing various prevention and control types. As in Singapore, the quantity of dengue cases reported in 2016 compared to 2015 decreased. This shows the effectiveness of prevention and control measures implemented within the country. Therefore, Singapore has shown significant improvements within the implementation and prevention of dengue cases. Therefore, improving enforcement and guidelines is extremely important in strengthening the prevention and control of dengue in Malaysia, which may ultimately reduce dengue during this country.

\section{Summary}

A total of 20 published article systematic surveys were included, a complete of 28 relevant references were identified by database literature search. The articles are found in database; Google Scholar and the online of Science Core Collection which performed well, achieving an overall score of systematic reviews. This comparative study provides an in-depth literature review of existing laws and guidelines to stop and control dengue outbreaks. Background and knowledge on dengue at Malaysian construction sites shows that construction projects in Malaysia account for the best number of dengue cases. Therefore, analysing the present implementation helps to work out the effectiveness of Malaysia's current laws and guidelines. Existing enforcement implemented in Malaysia is analysed and compared with other countries like Singapore. Malaysia is understood for its rapid development and urbanization. The rapid changes going down in Malaysia seem to be increasing the quantity of dengue cases, possibly thanks to the shortage of enforcement in controlling vector-borne diseases.

Thus, to investigate the effectiveness of existing enforcement implemented in Malaysia, a comparative perspective with countries like Singapore is required to research the efficiency of dengue prevention control mechanisms.

\section{Refference}

Abdelrazec, A., Belair, J., Shan, C., \& Zhu, H. (2016). Modeling the spread and control of dengue with limited public health resources. Mathematical Biosciences. https://doi.org/10.1016/j.mbs. 2015.11.004

Abidemi, A., \& Aziz, N. A. B. (2020). Optimal control strategies for dengue fever spread in Johor, Malaysia.Computer Methods and Programs in Biomedicine. https://doi.org/10.1016/j.cmpb. 2020.105585

Agusto, F. B., \& Khan, M. A. (2018). Optimal control strategies for dengue transmission in pakistan. Mathematical Biosciences. https://doi.org/10.1016/j.mbs.2018.09.007

Ahmad, R., Suzilah, I., Najdah, W., M., A., W., Topek, O., Mustafakamal, I., \& Lee, H., L. (2018). Factors determining dengue outbreak in Malaysia. PLoS ONE. https://doi.org/10.1371/ journal.pone.0193326 
Basar, S., \& Ismail, Z. (2016). Review of the existing policies pertaining to dengue in construction projects and identification of gap in research. Jurnal Teknologi. https://doi.org/10.11113/j t.v78.7134

Basar, S., Ismail, Z., \& Nasir, N. M. (2017). A review of the existing guidelines and legislations on dengue prevention measures being implemented in the Malaysian construction projects. Advanced Science Letters. https://doi.org/10.1166/asl.2017.7620

Basar, S., Ismail, Z., \& Nasir, N., M. (2018). Bibliometric Analysis of Research Methods in Dengue Related Research. Advanced Science Letters. https://doi.org/10.1166/asl.2018.12417

Basar, S., Nawi, M. N. M., \& Ismail, Z. (2018). Spatial analysis monitoring on dengue in Malaysia: From the perspective of the construction industry. Malaysian Construction Research Journal.

Capeding, M. R., Tran, N. H., Hadinegoro, S. R. S., Ismail, H. I. H. M., Chotpitayasunondh, T., Chua, M. N., \& Bouckenooghe, A. (2014). Clinical efficacy and safety of a novel tetravalent dengue vaccine in healthy children in Asia: A phase 3, randomised, observer-masked, placebocontrolled trial. The Lancet. https://doi.org/10.1016/S0140-6736(14)61060-6

Chang, A. Y., Fuller, D. O., Carrasquillo, O., \& Beier, J. C. (2014). Social Justice, Climate Change, and Dengue - Health and Human Rights Journal. Health and Human Rights Journal.

Cheong, Y. L., Burkart, K., Leitao, P. J., \& Lakes, T. (2013). Assessing weather effects on dengue disease in Malaysia. International Journal of Environmental Research and Public Health. https://doi.org/10.3390/ijerph10126319

Dye, C. (1986). Vectorial capacity: Must we measure all its components? Parasitology Today. https://doi.org/10.1016/0169-4758(86)90082-7

Rozilawati, H., Tanaselvi, K., Nazni, W. A., Masri, M. S., Zairi, J., Adanan, C. R., Lee, H. L. (2015). Surveillance of aedes albopictus skuse breeding preference in selected dengue outbreak localities, peninsular malaysia. Tropical Biomedicine.

Hamdan, N., Izzati, \& Kilicman, A. (2021). The development of a deterministic dengue epidemic model with the influence of temperature: A case study in Malaysia. Applied Mathematical Modelling. https://doi.org/10.1016/j.apm.2020.08.069

Harapan, H., Rajamoorthy, Y., Anwar, S., Bustamam, A., Radiansyah, A., Angraini, P., \& Muller, R. (2018). Knowledge, attitude, and practice regarding dengue virus infection among inhabitants of Aceh, Indonesia: A cross-sectional study. BMC Infectious Diseases. https://doi.org/ 10.1186/s12879-018-3006-z

Kyle, J. L., \& Harris, E. (2008). Global spread and persistence of dengue. Annual Review of Microbiology. https://doi.org/10.1146/annurev.micro.62.081307.163005

Lim, K. W., Sit, N. W., Norzahira, R., Sing, K. W., Wong, H. M., Chew, H. S., \& Vasan, S. S. (2010). Dengue vector surveillance in insular settlements of Pulau Ketam, Selangor, Malaysia. Tropical Biomedicine.

Ministry of Health Malaysia. (2011). Country Health Plan 2011 - 2015. Country Health Plan : 10th Malaysia Plan 2011-2015.

Muhammad, A. N. A., Salleh, S., Neoh, H. M., Zakaria, S., \& Jamal, R. (2011). Dengue epidemic in Malaysia: Not a predominantly urban disease anymore. BMC Research Notes. https://doi.org/10.1186/1756-0500-4-216 
Nazni, W. A., Hoffmann, A. A., NoorAfizah, A., Cheong, Y. L., Mancini, M. V., Golding, N., \& Sinkins, S. P. (2019). Establishment of Wolbachia Strain wAlbB in Malaysian Populations of Aedes aegypti for Dengue Control. Current Biology. https://doi.org/10.1016/j.cub.2019.11.007

Ng, L. C., Tan, L. K., Tan, C. H., Tan, S. S. Y., Hapuarachchi, H. C., Pok, K. Y., \& Khoo, S. P. (2009). Entomologic and virologic investigation of chikungunya, Singapore. Emerging Infectious Diseases. https://doi.org/10.3201/eid1508.081486

Ong, S. Q. (2016). Dengue vector control in Malaysia: A review for current and alternative strategies. Sains Malaysiana.

Perich, M. J., Kardec, A., Braga, I. A., Portal, I. F., Burge, R., Zeichner, B., C., ... Wirtz, R. A. (2003). Field evaluation of a lethal ovitrap against dengue vectors in Brazil. Medical and Veterinary Entomology. https://doi.org/10.1046/j.1365-2915.2003.00427.x

Phillips, M. L. (2008). Dengue reborn: Widespread resurgence of a resilient vector. Environmental Health Perspectives. https://doi.org/10.1289/ehp.116-a382

Sampaio, A. M. M., Kligerman, D. C., \& Junior, S. F. (2009). Dengue, related to rubble and building construction in Brazil. Waste Management. https://doi.org/10.1016/j.wasman.2009.06.017

Von Hippel, E. (2015). Foreword: Progress in research on user innovation. Journal of Engineering and Technology Management - JET-M. https://doi.org/10.1016/j.jengtecman.2015.09.002

World Health Organization. (2020). Dengue Situation Update Number 450 Update on the dengue situation in the Western Pacific Region Northern Hemisphere. WHO, (450), 1-7. 